\title{
The Impact of Urban Texture in Outdoor Thermal Comfort
}

\author{
Ani Tola Panariti ${ }^{*}$, Andrea Maliqari $^{2}$, Parashqevi Tashi $^{3}$ \\ ${ }^{1}$ Faculty of Architecture and Urban Design, Polytechnic University of Tirana, Rruga "Muhamet Gjollesha”, 54 Tiranë \\ ${ }^{2}$ Faculty of Architecture and Urban Design, Polytechnic University of Tirana, Rruga "Muhamet Gjollesha", 54 Tiranë \\ ${ }^{3}$ Faculty of Architecture and Urban Design, Polytechnic University of Tirana, Rruga "Muhamet Gjollesha", 54 Tiranë
}

\begin{abstract}
This article discusses the impact of urban texture in outdoor thermal comfort analyzing the coastal promenade, in the city of Durres, Albania, as a case study. At the beginning of this research, it is provided an assessment of the existing urban texture. Then, field measurements about air temperature, relative air humidity, wind speed, dew point and thermal radiation, obtained at two parts of the promenade with different urban texture are presented. After that, the findings are evaluated in terms of urban thermal comfort. In conclusion, the findings have indicated that on 22 June 2013, surface heat island (SHI) is critically present in the afternoon. The wellstudied use of different materials, green areas and water reduces the thermal radiation in promenades. In terms of urban thermal comfort, the results have shown that the arbitrary use of urban texture, such as in the case of Durrës' Promenade, influences the outdoor thermal comfort.
\end{abstract}

Keywords: outdoor thermal comfort, urban heat islands, heat emission, urban texture

\section{Introduction}

This article discusses the impact of urban texture in outdoor thermal comfort analyzing the coastal promenade, in the city of Durres, Albania, as a case study. Due to its geographic position, the promenade is all day long completely exposed to the solar radiation. The Coastal Promenade of Durres city is used by pedestrians in different weather conditions during the year. During the summer in afternoon, pedestrians use the promenade mainly after 7:30 pm. The sea breeze effect can be felt after 11:00 pm. During this time, pedestrians still feel hot. In spring and autumn people feel neither too cold nor too hot, because of its air temperature. During winter the pedestrians feel cold when it is cloudy and windy and not too cold when it is sunny.

In Mediterranean climate with a hot, dry summer and a cool winter, the heat emission by urban texture is one of the most influential variables in regards of thermal comfort in open urban spaces. Thermal Comfort is defined as the "condition of mind that expresses satisfaction with the thermal environment" (ASHRAE, 1997). The variables influencing thermal comfort are (Johansson, 2006):

a) Urban Texture, which includes surface materials, green areas, vegetation, water and shadings.

b) Urban Morphology, which consist on the ratio between the height of building façade and the width of the street. It is expressed as $\mathrm{H} / \mathrm{W}$, respectively.

c) Climate Conditions, such as air temperature, air humidity, wind speed and sea breeze, solar radiation, rainfall and vapor pressure.

d) Pedestrian Movements, which includes types and flux of spatial movements.

e) Urban Heat Islands, which refers to the observed temperature differences urban environments and the surrounding rural areas.
Cities are warmer than their rural surroundings. The urban heat island (UHI), which is primarily a nocturnal phenomenon, has been studied extensively throughout the 20th century (see e.g. (Oke, 1982), (Arnfield, 2003)). Three types of UHI are distinguished in the literature (Giguère, 2009):

1) Surface Heat Islands

2) Canopy Layer Heat Islands

3) Boundary Layer Heat Islands

The study is limited to the microclimate in promenade, taking Durres' Promenade as a case study. The research is mainly focused on analyzing the temperature measured from the infrared energy which is emitted by urban texture. The objective of this research is to show how much influence has the use of urban texture in outdoor thermal comfort.

\section{Methodology}

This research is experimental and analytic. At the beginning of this research, is provided an assessment of the existing urban texture. Then, it is presented field measurements about air temperature, relative air humidity, wind speed, dew point and thermal radiation, obtained at two parts of the promenade with different urban texture in 9 different spots of the promenade using Testo435, and Testo875i for thermal images. Measurements are done in the summer, 22 June 2013 and in the winter, 31 December 2013, in different times of the day. The first part and second part of promenade are composed with concrete tiles, grass, green vases, and a concrete layer used for a concert scene. The third part is designed with granite tiles, wooden texture that covers a concrete structure. As the western part (part 3) and the middle part (part 2) have the same urban texture, the measurements are focused only in part 3 . Because the western part (part 3) of promenade is built with different 


\section{International Journal of Science and Research (IJSR) \\ ISSN (Online): 2319-7064}

Index Copernicus Value (2013): 6.14 | Impact Factor (2014): 5.611

materials from the eastern part (part 1), which has classic ones, the measurements has shown different values of heat emission.

Based on that are done two comparative results. The first one compares the emitted temperature of the urban texture and air temperature in the afternoon, in summer and winter, while pedestrians go for leisure walk. The second one compares the western part (part 3) and eastern part (part 1) of promenade in order to find out whether the urban texture has been considered properly in the design process. The findings between the two parts of the promenade are evaluated in terms of urban thermal comfort. The research determines how much influence has the emitted temperature (thermal radiation) by the existing urban texture in promenades.

\section{Data Analysis}

In 2009 Durrës' Municipality has redesigned the western part of the promenade. The eastern part of the promenade was completed in 2004. In Fig. 1 is given a map of the promenade with its legend. The promenade is divided in three parts as shown in Fig.1. The first and second part of promenade are composed with concrete tiles, grass, green vases, and a concrete layer used for a concert scene. The third part has a different urban texture. It is designed with granite tiles, wooden texture that covers a concrete structure. Below in Tab. 1 is given a percentage of the used materials in the ratio of total area for each part of promenade.

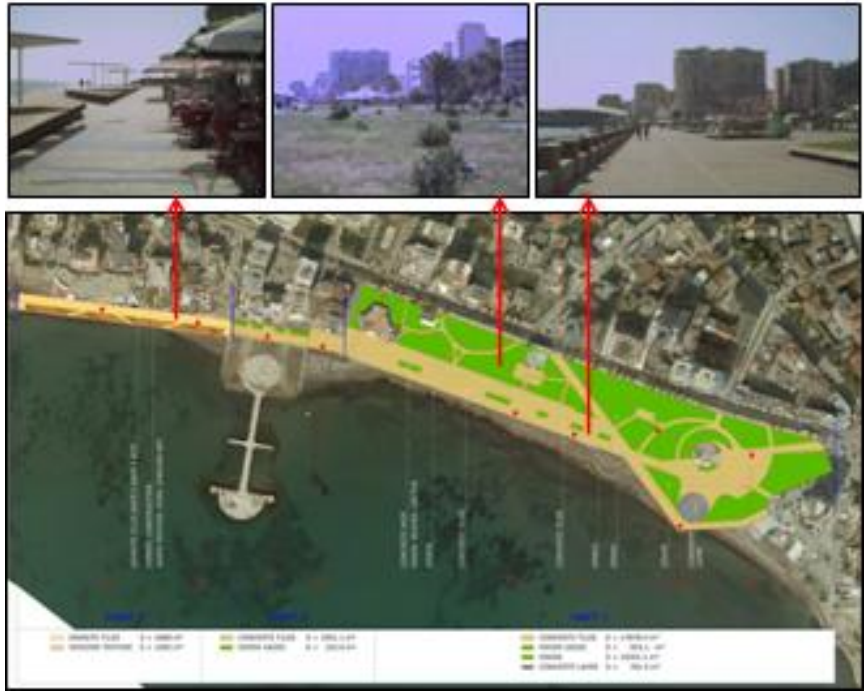

Figure 1: Promenade Map

Table 1: The ratio of Urban Texture

\begin{tabular}{|c|c|c|c|}
\hline Urban Texture & Part 1 & Part 2 & Part 3 \\
\hline $\mathrm{S}_{\text {tot }}\left(\mathrm{m}^{2}\right)$ & 42464.1 & 2194.7 & 3780 \\
\hline Wood (\%) & - & - & 28.8 \\
\hline Granite Tiles (\%) & - & - & 71.2 \\
\hline Concrete Tiles (\%) & 42.1 & 89 & - \\
\hline Green Vases (\%) & 1.1 & 11 & - \\
\hline Grass (\%) & 45.4 & - & - \\
\hline
\end{tabular}

In Fig. 2 are shown the average measurements of climate conditions on 22 June 2013. Air temperature, wind speed, air temperature and dew point are measured with Testo435, at 08:00, 12:00, 16:00 and 20:00.

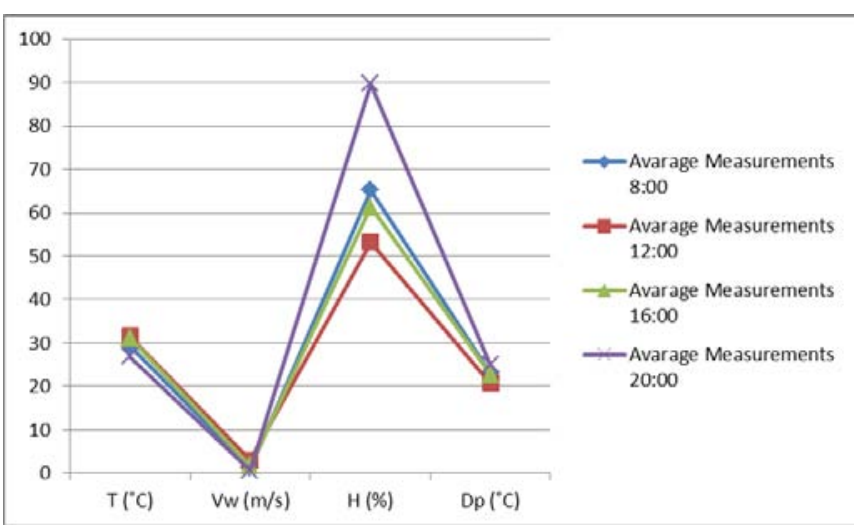

Figure 2: Average measurements, 22.06.2013

In Fig. 3-a,b,c are shown thermal measurements using thermal camera Testo875i, at 20:00. This time is the most critical one, as during summer, surfaces' materials emit solar temperature which is absorb during the day. Also at this time the promenade is very crowded and is used for leisure walk by pedestrians. The thermal graphs are elaborated with IRSoft - software.

The light yellow color shows the hottest spots and the dark blue shows the coldest spots on the promenade. The black horizontal line on thermo images shows the line section in promenade.

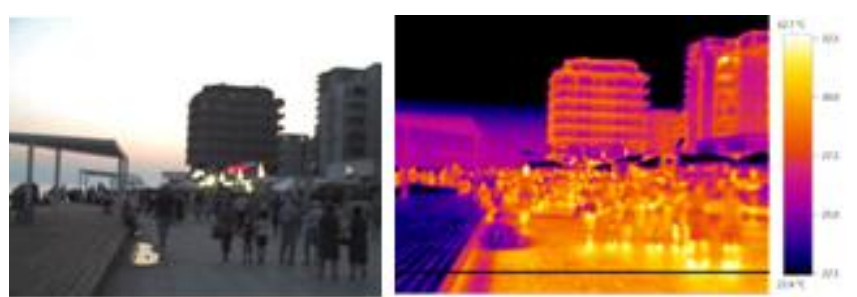

Figure 3-a: Thermal measurements, 22.06.2013, at 20:00 (part 1)

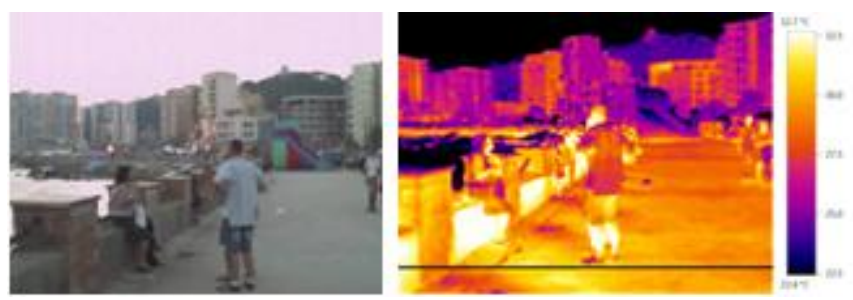

Figure 3-b: Thermal measurements, 22.06.2013, at 20:00 (part 3)

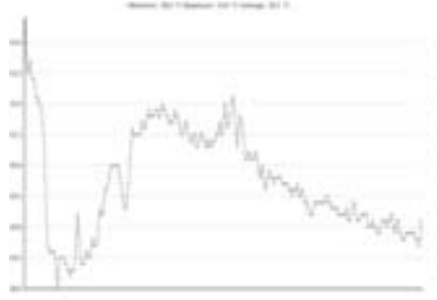

Part 1

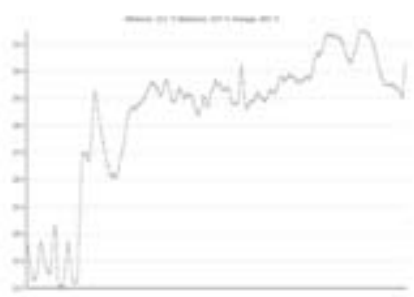

Part 3
Figure 3-c: Thermal measurements, temperature graph in section line, 22.06.2013, at 20:00

In Fig.4 is drawn a graph using Microsoft Office Excel 2007, in which are written down the measurements taken by thermal camera. In this graph is shown the emitted 


\section{International Journal of Science and Research (IJSR) \\ ISSN (Online): 2319-7064}

Index Copernicus Value (2013): 6.14 $\mid$ Impact Factor (2014): 5.611

temperature level for each material used in promenade, during four times of the day.

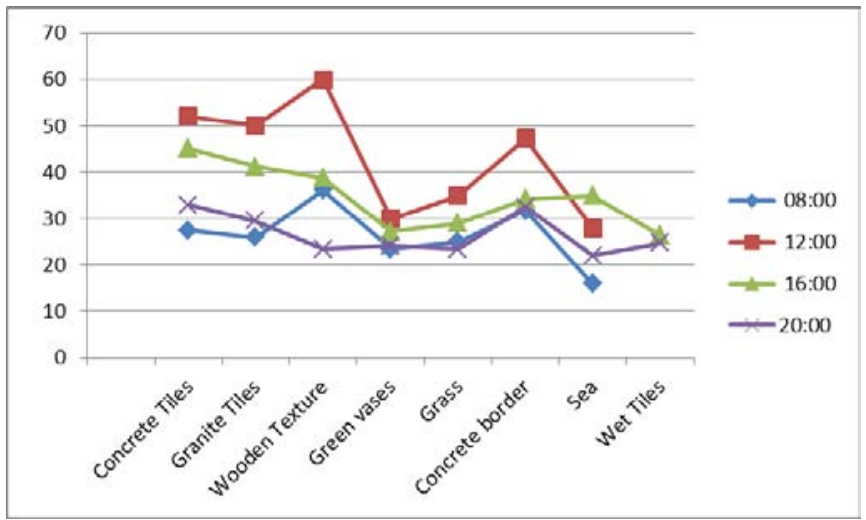

Figure 4: Emitted temperature graphic, 22.06.2013

In Fig.5 are shown the average measurements of climate conditions on 31 December 2013. Air temperature, wind speed, air temperature and dew point are measured with Testo435, at 09:00, 13:00 and 17:00.

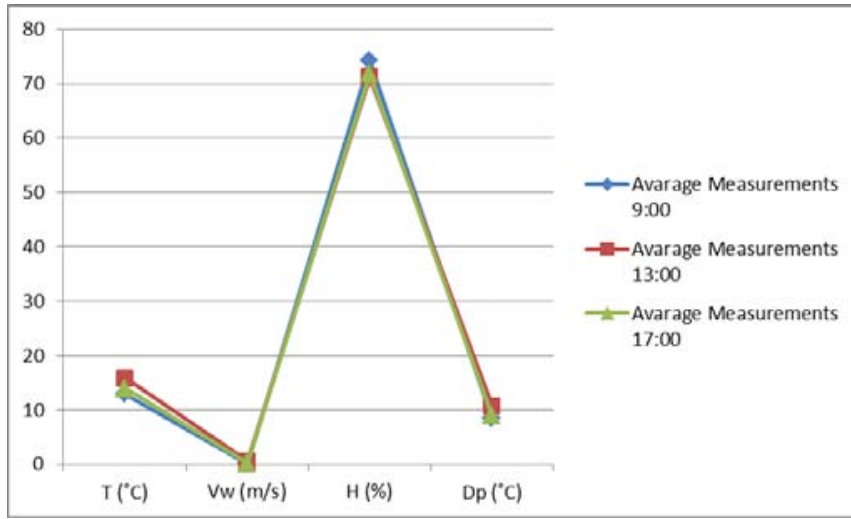

Figure 5: Average measurements, 31.12.2013

In Fig.6-a,b,c are shown thermal measurements using thermal camera Testo875i, at 17:00. During winter time the surface heat islands are not critical. The climate conditions in December for this year weren't so cold. It was not a usual day, as a winter time in Durres. Also at this time the promenade is used for leisure walk by pedestrians, but the flux of movement is not crowded as in summer. The thermal graphs are elaborated with IRSoft - software.

The light yellow color shows the hottest spots and the dark blue shows the coldest spots on the promenade. The black horizontal line on thermo images shows the line section in promenade.
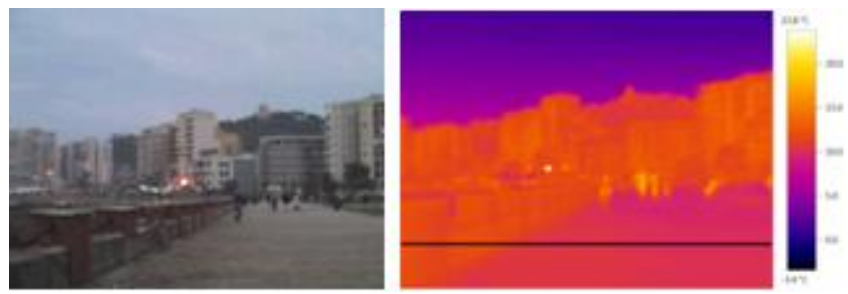

Figure 6-a: Thermal measurements, 31.12.2013, at 17:00 (part 1)
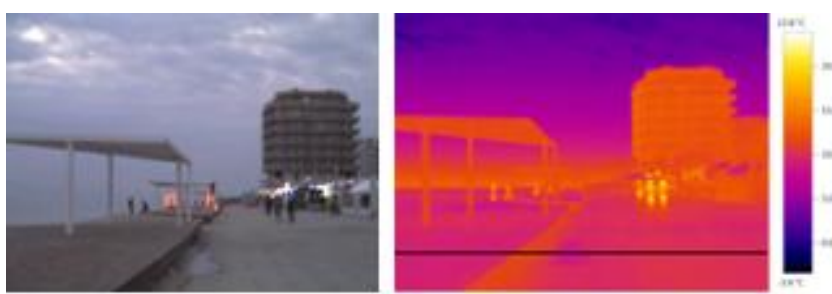

Figure 6-b: Thermal measurements, 31.12.2013, at 17:00 (part 3)

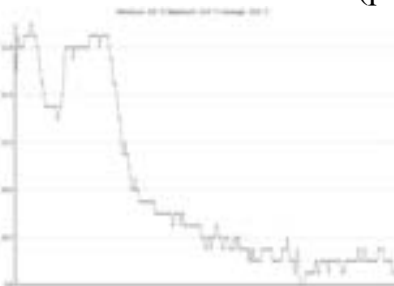

Part 1

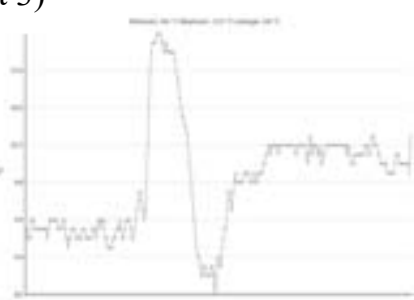

Part 3
Figure 6-c: Thermal measurements, temperature graph in section line, 31.12.2013, at 17:00

In Fig. 7 is drawn a graph using Microsoft Office Excel 2007, in which are written down the measurements taken by thermal camera. In this graph is shown the emitted temperature level for each material used in promenade, during three times of the day.

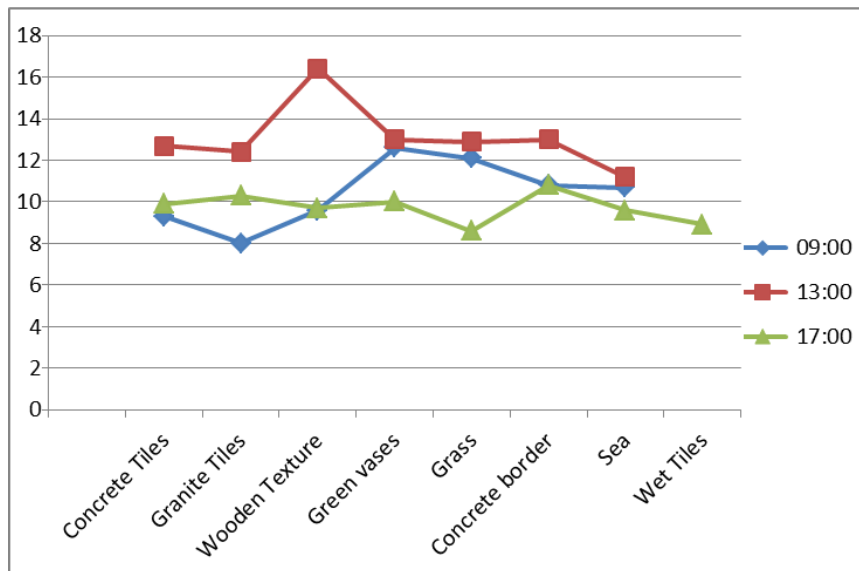

Figure 7: Emitted temperature graphic, 31.12.2013

\section{Findings}

Thermal measurements have indicated that on 22 June 2013, during the day is impossible for pedestrians go for leisure walk, as it is too hot and the area is without shading elements. People still feel hot, even at 20:00. This is mainly incurred by the heat emission of surfaces' materials used in promenade. Looking at the graph in Fig. 2, climate conditions parameters in June at 20:00, shows that: air temperature $\mathrm{T}=27^{\circ} \mathrm{C}$, air humidity $\mathrm{H}=80 \%$, wind speed $\mathrm{W}=0.56 \mathrm{~m} / \mathrm{s}$, and dew point $\mathrm{Dp}=24.9^{\circ} \mathrm{C}$.

Based on the graph in Fig.4 it has been done a comparison between part 1 and part 3 of promenade, which has different urban texture. It has been found that green vases, grass, wet tiles (in part 3 ) are cooler $9-10^{\circ} \mathrm{C}$ than concrete/granite tiles (part 1). If we compare only the tiles it has been pointed out that granite tiles are cooler $4^{\circ} \mathrm{C}$ than concrete tiles. Also wooden texture is cooler $11^{\circ} \mathrm{C}$ than granite/concrete. During 


\section{International Journal of Science and Research (IJSR) \\ ISSN (Online): 2319-7064 \\ Index Copernicus Value (2013): 6.14 | Impact Factor (2014): 5.611}

the measurements, in part 3 of promenade, granite tiles were watered, so we had recognized that wet tiles have the same temperature as grass, $24^{\circ} \mathrm{C}$. It is necessary to mention that the grass was not well-maintained and concrete/granite tiles are warmer $5-3^{\circ} \mathrm{C}$ than air temperature.

On 31 December 2013 thermal measurements have shown that during the day pedestrians can go for leisure walk, but it is not so crowded such as in summer. Looking on graph in Fig.5 in December at 17:00 measurements of climate conditions have indicated that air temperature is $\mathrm{T}=14^{\circ} \mathrm{C}$, air humidity is $\mathrm{H}=71 \%$, wind speed is $\mathrm{W}=0.17 \mathrm{~m} / \mathrm{s}$ and dew point is $\mathrm{Dp}=8.94^{\circ} \mathrm{C}$.

Based on the graph in Fig.7 it has been done a comparison between part 1 and part 3 of promenade. Both parts have different urban texture. From the comparison it has been found that emitted temperature of green vases and grass is respectively $8.9-10^{\circ} \mathrm{C}$, and wooden texture is $10^{\circ} \mathrm{C}$. Comparing only the tiles, it is pointed out that granite tiles have the same temperature as concrete tiles $10^{\circ} \mathrm{C}$. During this time, some granite tiles were watered so the measurements have indicated that wet tiles have the same temperature as grass $8.9 \mathrm{c}$. It is necessary to mention that the grass was maintained naturally and concrete/granite tiles are colder $4^{\circ} \mathrm{C}$ than air temperature.

At the end is done a comparison between Emitted Temperature and Air Temperature, at the moment when pedestrians go for a leisure walk. In Tab. 2 and Tab. 3 are presented respectively the values on 22 June 2013 at 20:00 and on 31 December 2013 at 17:00. Looking at the Tabs during the winter the urban texture is $3-5^{\circ} \mathrm{C}$ colder than air temperature. During the summer some of the urban texture such as granite tiles, concrete tiles and concrete vases are 2$6^{\circ} \mathrm{C}$ hotter than air temperature. While the wet tiles, wooden texture and grass green vases are $2^{\circ} \mathrm{C}$ cooler than air temperature.

Table 2: Comparison between Emitted Temperature and Air Temperature in summer

\begin{tabular}{|c|c|c|c|c|c|c|c|c|}
\hline \multicolumn{8}{|c|}{ Comparison between Emitted Temperature and Air Temperature } \\
\hline dt.22.06.2013 time 20:00 & $\begin{array}{c}\text { Granite } \\
\text { Tiles }\end{array}$ & Wet Tiles & $\begin{array}{c}\text { Wooden } \\
\text { Texture }\end{array}$ & $\begin{array}{c}\text { Concrete } \\
\text { Tiles }\end{array}$ & Green vases & Grass & $\begin{array}{c}\text { Concrete } \\
\text { border }\end{array}$ & $\begin{array}{c}\text { Sea } \\
\text { Part 1 }\end{array}$ \\
\hline & \multicolumn{7}{|c|}{ Part 3 } \\
\hline Emitted Temperature (ET) & 29.5 & 24.8 & 23.4 & 33 & 24.2 & 23.5 & 32.5 & 22 \\
\hline Air Temperature (AT) & 26.8 & 26.8 & 26.8 & 26.8 & 26.8 & 26.8 & 26.8 & 26.8 \\
\hline Differences (ET-AT) & 2.7 & -2 & -3.4 & 6.2 & -2.6 & -3.3 & 5.7 & -4.8 \\
\hline Dotes: & \multicolumn{7}{|c|}{ Negative values - Lower } \\
\hline
\end{tabular}

Table 3: Comparison between Emitted Temperature and Air Temperature in winter

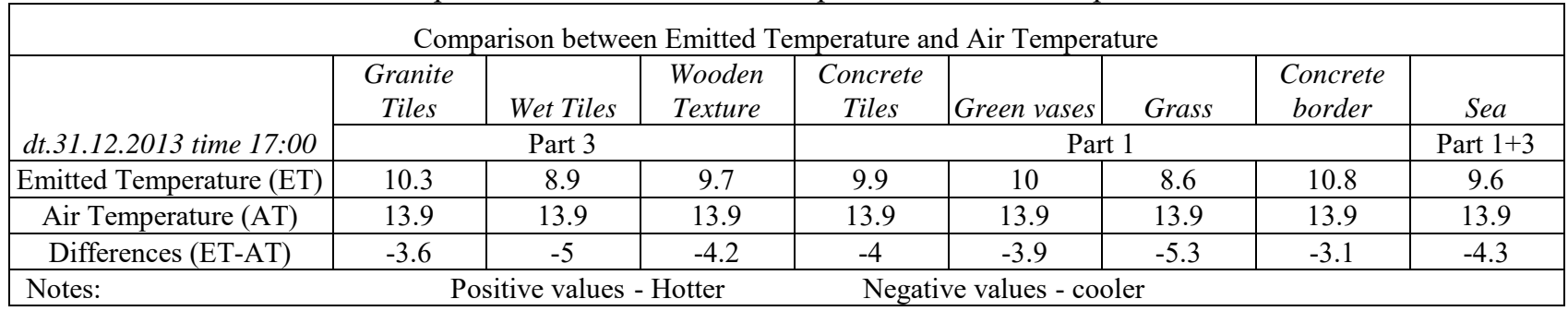

\section{Conclusions}

The comparative results lead to two main conclusions. The first one is that during the summer granite tiles, concrete tiles and concrete vases are $2-6^{\circ} \mathrm{C}$ hotter than air temperature. While the wet tiles, wooden texture, grass green vases are $2^{\circ} \mathrm{C}$ cooler than air temperature. As pedestrians go for leisure walk during that time, the presence of surface heat islands make the walk uncomfortable. On 31 December 2013 thermal measurements have shown that surface heat islands (SHI) are not presented, so pedestrians can go for leisure walk during the day.

The second conclusion, is that the part 3 is approximately 2$4^{\circ} \mathrm{C}$ cooler than part 1 . Looking on the Tab. 2 is pointed out that granite tiles are $4^{\circ} \mathrm{C}$ cooler than concrete tiles. Wooden texture has the same values as the grass which is not watered. Moreover, an irrigated green area can be considerably cooler than their surroundings, even during day time, especially in semi-arid and arid areas.
Summing up, the findings have indicated that on 22 June 2013, surface heat island (SHI) is critically present in the afternoon. The criteria of urban thermal comfort and urban microclimate seem not to be taken into consideration during the urban design process in both parts of the promenade. The well-studied use of different materials, green areas and water reduces the thermal radiation in promenades. In terms of urban thermal comfort, the results have shown that the arbitrary use of urban texture, such as in the case of Durrës' Promenade, influences the outdoor thermal comfort.

\section{Other recommendations}

Two basic issues are highlighted in this research; vegetation and pavements.

Vegetation can play a significant role in regulating the urban microclimate and can influence operational energy demand through solar absorption and the cooling effects provided by shade and evapotranspiration (Giguère, 2009). In this condition it is recommended to increase green areas,

\section{Volume 4 Issue 12, December 2015}


in both parts of promenade. Water the pavements with recycle water, so the temperature will be the same as in vegetated area (Yamagata, 2008). Moreover watering green areas and pavements can be considerably cooler than their surroundings, even during noon time.

The thermal properties of surface materials also greatly influence the urban climate (Arnfield, 2003). High albedo materials, adding reflective pigments to concrete tiles (Lawrence Berkeley National Laboratory) will absorb less solar radiation. This can be applicable at the promenade but not in big surfaces, because it will have high reflection. It is recommended, also, the use of permeable or porous paving, as allows water to filter into the ground, keeping the pavement cool at night.

\section{References}

[1] Arnfield, A. (2003). Two decades of urban climate research: a review of turbulence, exchanges of energy and water, and the urban heat island. Int. J. Climatol., 23.

[2] ASHRAE. (1997). Handbook: Fundamentals (SI. Atalanta: American Society of Heating, Refrigerating and Air-Conditioning Engineers.

[3] Giguère, M. M. (2009). Urban Heat Island Mitigation Strategies. Québec: Direction de la santé environnementale et de la toxicologie.

[4] Johansson, E. (2006). Urban Design and Outdoor Thermal Comfort in Warm Climates. Sweden: Lund University.

[5] Oke, T. (1982). The energetic basis of the urban heat island. Quart. Journal of Royal Meteorological, 1-24.

[6] Yamagata, H. N. (2008). Heat island mitigation using water retentive pavement sprinkled with reclaimed wastewater, Water science \& technology. Wastewater and Sludge Management Division, National Institute for Land and Infrastructure Management: Ibaraki, Japan.

\section{Author Profile}

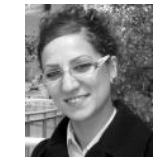

Ani Tola (Panariti) is graduated from the Faculty of Civil Engineering, Department of Architecture in 2008. She is a $\mathrm{PhD}$ candidate (student) at the Faculty of Architecture and Urbanism, Polytechnic University of Tirana. Her research field is the improvement of urban thermal comfort in the coastal promenades. Her academic experience started in 2009 when she joined the academic staff of the Department of Architecture and Urbanism at the Faculty of Civil Engineering, Polytechnic University of Tirana. She has been a member of "American Institute of Architects" from 2010-2012. 